\title{
Current safety situation at level crossings in Croatia and the future research
}

\author{
D. Badanjak, D. Barić \& L. Novačko \\ University of Zagreb, Faculty of Transport and Traffic Sciences, Croatia
}

\begin{abstract}
Level crossings (LCs ) represent a direct conflict between rail and road traffic. From the aspect of safety, LCs are traffic points of high risk. This is confirmed by the fact that they are often places where traffic incidents and accidents frequently occur, with consequences in human victims and great material damage. Those represent an actual problem of traffic safety which is characteristic of the traffic system of every country and in the Republic of Croatia as well. In Croatia every level crossing is protected in accordance with the stipulated legal regulations, and the protection level primarily depends on the category of the railway line (main, regional, and local) and the road (state, county, local, uncategorized), allowed speed on the line, terrain conditions, and local circumstances at the crossing location. On the Croatian Railways network in the total length of $2756 \mathrm{~km}$, there are a total of $1542 \mathrm{LCs}$. Out of the total number of LCs $68.4 \%$ are protected only by road traffic signs and visibility triangle (signs informing about the approach to the crossing, STOP sign and Andrew's cross), and 31.6\% of LCs are protected by devices (light-audio signals, half-barriers, barriers). The safety condition at level crossings in the Republic of Croatia is best reflected in the data on the number of traffic incidents and accidents (fatalities and material damage), as well as on the number of victims (killed or injured). This paper will introduce the current status of level crossings in Croatia, included types of LCs, statistical data of accidents, comparison with other countries, national safety programme for the protection of LCs, and research perspectives with aim of defining priority measures of improving safety at level crossings.
\end{abstract}

Keywords: level crossings, safety, Republic of Croatia. 


\section{Introduction}

The total length of the railway network in Croatia is $2722.41 \mathrm{kms}$, which currently accommodates 1542 level crossings. In compliance with the legal regulations, all of them are protected in one of the foreseen ways $(30 \%$ with protection devices, and $70 \%$ with road-traffic warning signs) [1].

Since level crossings are points of direct conflict between rail and road traffic, they represent collision points of two traffic systems, where often emergencies occur, sometimes with the severest consequences (material damage and fatalities). Therefore, safety of rail and road traffic at level crossings is extremely at risk, and the level crossings represent a serious safety problem.

The analyses carried out of the accident causes indicate that in spite of technical and technological improvements of protection systems, the number of accidents continues to be significant which refers to the primary responsibility of traffic participants (motorists of road vehicles and pedestrians) and only then of the equipment. In order to solve the safety problems at level crossings the research is necessary with the aim of improving the system from the technical and technological aspect, also requiring the analysis of the emergency causes [2].

A significant international project dealing with the problems of level crossings is SELCAT (Safer European Level Crossing Appraisal and Technology) as part of the FP 6 Program (area of "Sustainable Surface Transport Coordination Actions"), with the aim of harmonizing the approach to problem solving at the European level [3].

In Croatia the Program of solving the level crossings in the Republic of Croatia is topical, and it includes 1032 crossings. The planned deadline to solve these problems is 15 years, and the estimated value of the entire program amounts to about 122 million euro [4].

\section{Overview of legislation at international and national levels}

\subsection{Overview of legislation at international level}

As part of EU regulations that refers to the problems regarding rail infrastructure and traffic safety it is necessary to emphasize the following:

- Directive 2001/16/EC on the Interoperability of the Trans-European Conventional Rail System;

- Directive 96/48/EC on the Interoperability of the Trans-European HighSpeed Rail System;

- $\quad$ Directive 2004/49/EZ on the Railway Safety;

- $\quad$ Directive 91/440/EEC on the Development of the Community's Railways;

- $\quad$ Directive 2001/12/EC amending Directive 91/440/EEC;

- $\quad$ Directive 2004/51/EZ amending Directive 91/440/EEZ

- Directive 2004/50/EZ about amendments of Directive 96/48/EZ and Directive 2002/16/EZ

Other significant relevant documents are:

- $\quad$ AGC - European Agreement on Main International Railway Lines; 
- AGTC - European Agreement on Important International Combined Transport Lines and Related Installations;

- TER - Trans-European Railway (Project of improving the railway parameters in Eastern and Central Europe).

\subsection{Overview of legislation at national level}

Legal and sub-legal regulations at the national level that determine the traffic, technological and technical conditions, infrastructure classification, method of operation and protection of rail and road traffic, conditions for safe traffic flow include [5-9]: Law on railways, Law on rail traffic safety, Law on road traffic safety, Law on public roads, Decision on classification of railway lines, Regulations on criteria, procedure, method of defining and protection of rail-road crossings, Regulations on the method and conditions for safe rail traffic flow.

Based on the mentioned laws, and in accordance to the provisions of Article 98 of the Law on Rail Traffic Safety and Article 21 of Regulations on criteria, procedure, method of defining and protection of level crossings, the Program on solving level crossings in the Republic of Croatia has been brought and it refers to the period from 2006 to 2015. Apart from this Program, the National program of railway infrastructure for the period from 2008 to 2012 should be mentioned, which defines the plans of constructing new, and modernization and maintenance of the existing rail network, as well as the funding sources including also solutions for level crossings.

\subsection{Program for solving level crossings in the Republic of Croatia}

The Program for solving LCs is a national program which is one of the preconditions for systemic solving of the LC problems. Apart from the necessary planned technical and technological measures, the Program also provides the dynamics and priorities in solving regarding the types of solutions (elimination and merging of crossings, reconstruction of the visibility triangle, elimination without merging, supplementation of devices by half-barriers, installation of $\mathrm{L}+\mathrm{S}$ instruments (light+sound), installation of $\mathrm{L}+\mathrm{S}+\mathrm{HB}$ (light + sound + halfbarriers) devices and level separation).

Table 1: $\quad$ Realization of The Program for solving LCs.

\begin{tabular}{|c|c|c|c|c|c|c|c|c|}
\hline \multirow{2}{*}{$\begin{array}{c}\text { Dynamics } \\
\text { (year) }\end{array}$} & \multicolumn{9}{|c|}{$\begin{array}{c}\text { Technical solution } \\
\text { elimination } \\
\text { and } \\
\text { merging }\end{array}$} & $\begin{array}{c}\text { reconstruction } \\
\text { of the } \\
\text { visibility } \\
\text { triangle }\end{array}$ & $\begin{array}{c}\text { elimination } \\
\text { without } \\
\text { merging }\end{array}$ & $\begin{array}{c}\text { supplementation } \\
\text { of devices by } \\
\text { half-barriers }\end{array}$ & L+S & $\begin{array}{c}\text { L+S } \\
+ \text { HB }\end{array}$ & $\begin{array}{c}\text { Level } \\
\text { separation }\end{array}$ & Total \\
\hline 2006 & 3 & 0 & 3 & 0 & 2 & 4 & 2 & 15 \\
\hline 2007 & 1 & 0 & 3 & 0 & 6 & 14 & 1 & 25 \\
\hline $09 / 2008$ & 0 & 0 & 3 & 0 & 8 & 8 & 0 & 19 \\
\hline Total & 4 & 0 & 9 & 0 & 16 & 26 & 3 & 59 \\
\hline
\end{tabular}


Table 2: $\quad$ The Program for solving LCs (dynamics, solution).

\begin{tabular}{|c|c|c|c|c|c|c|c|c|}
\hline \multirow[b]{2}{*}{$\begin{array}{c}\text { Dynamics } \\
\text { (year) }\end{array}$} & \multicolumn{8}{|c|}{ Technical solution } \\
\hline & $\begin{array}{l}\text { elimination } \\
\text { and merging }\end{array}$ & \begin{tabular}{|c|} 
reconstruction \\
of the \\
visibility \\
triangle \\
\end{tabular} & $\begin{array}{c}\text { elimination } \\
\text { without } \\
\text { merging }\end{array}$ & $\begin{array}{c}\text { supplementation } \\
\text { of devices by } \\
\text { half-barriers }\end{array}$ & $\mathrm{L}+\mathrm{S}$ & $\begin{array}{l}\mathrm{L}+\mathrm{S} \\
+\mathrm{HB}\end{array}$ & $\begin{array}{c}\text { Level } \\
\text { separation }\end{array}$ & Total \\
\hline 2006. & 28 & 4 & 29 & 6 & 30 & 24 & 24 & 126 \\
\hline 2007. & 10 & 16 & 3 & 20 & 14 & 40 & 40 & 109 \\
\hline 2008. & 27 & 11 & & 3 & 28 & 32 & 32 & 108 \\
\hline 2009. & 79 & 17 & & 12 & 19 & 23 & 23 & 159 \\
\hline 2010. & 27 & 11 & & & 50 & 19 & 19 & 116 \\
\hline 2011. & 64 & & & & 38 & 8 & 8 & 116 \\
\hline 2012. & 18 & & & 2 & 51 & 6 & 6 & 83 \\
\hline 2013. & 33 & & & & 32 & 5 & 5 & 75 \\
\hline 2014. & 36 & & & & 28 & 3 & 3 & 69 \\
\hline 2015 & 25 & & & & 26 & 3 & 3 & 61 \\
\hline $\begin{array}{l}2016 .- \\
2020 .\end{array}$ & & & & & & 10 & 10 & 10 \\
\hline Total & 347 & 59 & 32 & 43 & 316 & 166 & 69 & 1032 \\
\hline
\end{tabular}

\section{Basic characteristics of LCs on the Croatian railways network}

\subsection{Croatian railways network}

The total length of all the railway lines in the Republic of Croatia is $2722.41 \mathrm{~km}$, out of which $2468.54 \mathrm{~km}(90.7 \%)$ are single track lines and $253.87 \mathrm{~km}(9.3 \%)$ are double track railway lines. There are $980.07 \mathrm{~km}(36.0 \%)$ of electrified lines, out of which $824.37 \mathrm{~km}(84.1 \%)$ with single phase AC $25 \mathrm{kV} / 50 \mathrm{~Hz}$ system and $137.70 \mathrm{~km}(15.9 \%)$ with DC $3 \mathrm{kV}$ system. The railway lines in the Republic of Croatia have been classified into three categories [8]:

1) Railway lines significant for international traffic (M):

a) Main (corridor) lines - they pass through pan-European corridors or their branches;

b) Connection lines - they connect railway lines on pan-European corridors and their branches;

c) Linking lines - they connect the international sea and river ports in the Republic of Croatia;

2) Railway lines significant for regional traffic $(R)$;

3) Railway lines significant for local traffic (L).

In the process of integration of the Republic of Croatia into the European Union, the railway lines will be determined that will belong to the integral trans- 
European railway network, and until then the network of the main (corridor) railway lines consists of the railway lines that pass through the Pan-European traffic corridors $(\mathrm{X})$ and their branches $(\mathrm{Vb}$ and $\mathrm{Vc})$.

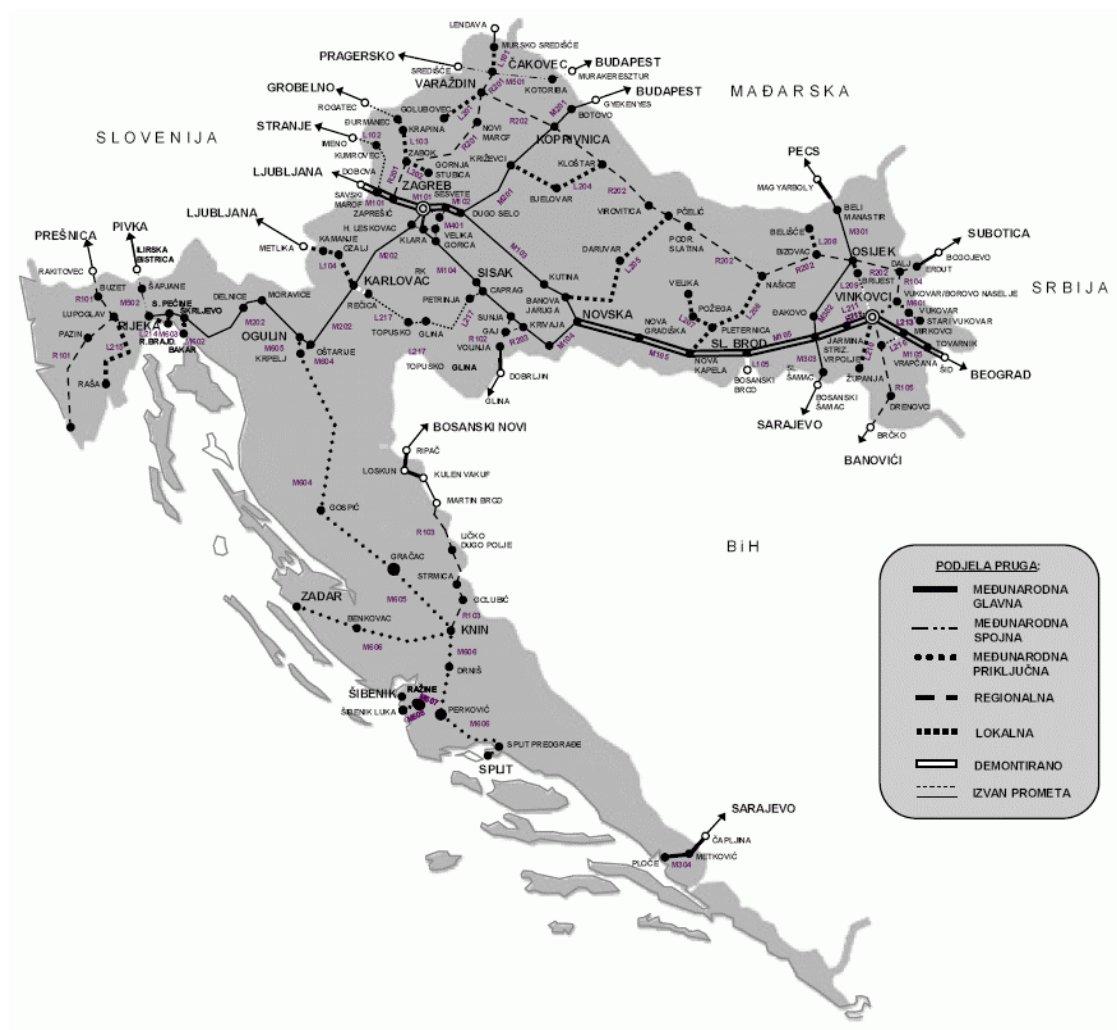

Figure 1: Network of Croatian Railways.

\subsection{LC protection method}

On the network of the Croatian railways there are no unprotected level crossings. Every level crossing, out of a total of 1542, has been protected in compliance with the stipulated legal regulations. The protection level depends on the rail line category (M, R, L) and road category (state, county, local, non-classified), permitted speed, terrain conditions, and local conditions at the point of intersection. Consequently, the level crossings may be protected by road traffic signs (minimally STOP sign and St. Andrew's cross) and visibility triangle, and there is a total of 1055 i.e. $68.41 \%$ such crossings; or by means of protection devices (automatic device - light-sound signals with or without half-barriers and mechanical device - barriers).

A significant technological indicator of safety is the density of level crossings in relation to the railway network length. The LC density is proportional to the 
number of crossings and inversely proportional to the length of the railway network. In Croatia it is 0.52 LCs per kilometre of railway line (Germany 0.56, France 0.65, UK 0.46, Poland 0.94, the Czech Republic 0.89).

Table 3: $\quad$ Number of LCs on the network of the Croatian railways, regarding the protection method.

\begin{tabular}{|c|c|c|c|}
\hline \multirow{2}{*}{ Year } & \multicolumn{2}{|c|}{ Protection method } & \multirow{2}{*}{ Total } \\
\cline { 2 - 3 } & traffic sign + visibility triangle & automatic / mechanical & \\
\hline 2001 & 1171 & 442 & 1613 \\
\hline 2002 & 1154 & 447 & 1601 \\
\hline 2003 & 1128 & 448 & 1576 \\
\hline 2004 & 1109 & 451 & 1560 \\
\hline 2005 & 1096 & 458 & 1554 \\
\hline 2006 & 1080 & 466 & 1546 \\
\hline 2007 & 1055 & 487 & 1542 \\
\hline
\end{tabular}

Table 4: $\quad$ Number of LCs on the network of Croatian railways, regarding the protection method and rail line category.

\begin{tabular}{|c|c|c|c|c|}
\hline \multirow[b]{2}{*}{ Year } & \multirow[b]{2}{*}{$\begin{array}{l}\text { Rail line } \\
\text { category }\end{array}$} & \multicolumn{2}{|c|}{ Protection method } & \multirow[b]{2}{*}{ Tota } \\
\hline & & $\begin{array}{c}\text { traffic sign }+ \\
\text { visibility } \\
\text { triangle } \\
\end{array}$ & $\begin{array}{l}\text { automatic / } \\
\text { mechanical }\end{array}$ & \\
\hline \multirow{3}{*}{2005} & $(\mathrm{M})$ & 329 & 282 & 611 \\
\hline & (R) & 296 & 114 & 410 \\
\hline & $(\mathrm{L})$ & 471 & 62 & 533 \\
\hline \multicolumn{4}{|r|}{ Total } & 1554 \\
\hline \multirow{3}{*}{2006} & (M) & 320 & 292 & 612 \\
\hline & (R) & 297 & 114 & 411 \\
\hline & (L) & 463 & 60 & 523 \\
\hline \multicolumn{4}{|r|}{ Total } & 1546 \\
\hline \multirow{3}{*}{2007} & (M) & 307 & 309 & 616 \\
\hline & $(\mathrm{R})$ & 289 & 114 & 403 \\
\hline & $(\mathrm{L})$ & 459 & 64 & 523 \\
\hline \multicolumn{4}{|r|}{ Total } & 1542 \\
\hline
\end{tabular}




\section{Safety on LCs in Croatia}

The traffic safety at level crossings means the safety of rail and road traffic. The safety condition at LCs in the Republic of Croatia is best reflected in the statistical data on the number of traffic accidents with consequences. The statistics and the overview of emergencies in the period from 2001 to 2007 are presented both in Tables [10-11].

Table 5: $\quad$ Share of traffic accidents at LCs in relation to the total number of accidents.

\begin{tabular}{|c|c|c|c|}
\hline Year & $\begin{array}{c}\text { Total number of } \\
\text { traffic accidents }\end{array}$ & $\begin{array}{c}\text { Number of traffic } \\
\text { accidents on LCs }\end{array}$ & Share (\%) \\
\hline 2001 & 81.911 & 578 & 0,71 \\
\hline 2002 & 86.611 & 530 & 0,61 \\
\hline 2003 & 92.102 & 517 & 0,56 \\
\hline 2004 & 76.540 & 487 & 0,64 \\
\hline 2005 & 58.132 & 454 & 0,78 \\
\hline 2006 & 58.203 & 496 & 0,85 \\
\hline 2007 & 61.020 & 514 & 0,84 \\
\hline Total & 514.519 & 3.576 & 0,70 \\
\hline
\end{tabular}

Table 6: Number of traffic incidents regarding the type of protection in the period from 2001 to 2007.

\begin{tabular}{|c|c|c|c|c|}
\hline \multirow{2}{*}{ Year } & \multicolumn{3}{|c|}{ Protection method LCs } & \multirow{2}{*}{ Total } \\
\cline { 2 - 4 } & $\begin{array}{c}\text { Physically } \\
\text { protected }\end{array}$ & $\begin{array}{c}\text { Light } \\
\text { signalization }\end{array}$ & $\begin{array}{c}\text { Unprotected (only } \\
\text { traffic sign) }\end{array}$ & \\
\hline 2001 & 243 & 109 & 226 & 578 \\
\hline 2002 & 250 & 99 & 181 & 530 \\
\hline 2003 & 290 & 107 & 120 & 517 \\
\hline 2004 & 283 & 87 & 117 & 487 \\
\hline 2005 & 274 & 80 & 100 & 454 \\
\hline 2006 & 311 & 91 & 94 & 496 \\
\hline 2007 & 303 & 96 & 115 & 514 \\
\hline Total & 1954 & 669 & 953 & 3576 \\
\hline
\end{tabular}


602 Safety and Security Engineering III

Table 7: $\quad$ Number of traffic incidents at LCs with victims.

\begin{tabular}{|c|c|c|c|c|}
\hline \multirow{2}{*}{ Year } & \multicolumn{3}{|c|}{ Protection method LCs } & \multirow{2}{*}{ Total } \\
\cline { 2 - 4 } & $\begin{array}{c}\text { Physically } \\
\text { protected }\end{array}$ & $\begin{array}{c}\text { Light } \\
\text { signalization }\end{array}$ & $\begin{array}{c}\text { Unprotected } \\
\text { (only traffic sign) }\end{array}$ & \\
\hline 2001 & 17 & 15 & 75 & 107 \\
\hline 2002 & 23 & 16 & 52 & 91 \\
\hline 2003 & 33 & 9 & 44 & 86 \\
\hline 2004 & 22 & 10 & 36 & 68 \\
\hline 2005 & 23 & 14 & 43 & 80 \\
\hline 2006 & 28 & 19 & 37 & 84 \\
\hline 2007 & 27 & 9 & 37 & 73 \\
\hline
\end{tabular}

Table 8: Number of fatalities, seriously, lightly injured in traffic accidents at LCs.

\begin{tabular}{|c|c|c|c|c|c|}
\hline \multirow[b]{2}{*}{ Year } & \multirow[b]{2}{*}{ Consequences } & \multicolumn{3}{|c|}{ Protection method LCs } & \multirow[b]{2}{*}{ Total } \\
\hline & & $\begin{array}{l}\text { Physically } \\
\text { protected }\end{array}$ & $\begin{array}{c}\text { Light } \\
\text { signalization }\end{array}$ & Unprotected & \\
\hline 2001 & \multirow{7}{*}{ fatalities } & 1 & 1 & 5 & 7 \\
\hline 2002 & & 2 & 4 & 8 & 14 \\
\hline 2003 & & 4 & 3 & 4 & 11 \\
\hline 2004 & & 3 & 5 & 4 & 12 \\
\hline 2005 & & 1 & 2 & 10 & 13 \\
\hline 2006 & & 1 & 4 & 11 & 16 \\
\hline 2007 & & -- & 3 & 6 & 9 \\
\hline 2001 & \multirow{7}{*}{$\begin{array}{l}\text { seriously } \\
\text { injured }\end{array}$} & 7 & 6 & 30 & 43 \\
\hline 2002 & & 7 & 8 & 14 & 29 \\
\hline 2003 & & 10 & 2 & 13 & 25 \\
\hline 2004 & & 7 & 5 & 14 & 26 \\
\hline 2005 & & 7 & 7 & 19 & 33 \\
\hline 2006 & & 12 & 5 & 11 & 28 \\
\hline 2007 & & 11 & 1 & 11 & 23 \\
\hline 2001 & \multirow{7}{*}{ lightly injured } & 13 & 12 & 89 & 114 \\
\hline 2002 & & 23 & 13 & 57 & 93 \\
\hline 2003 & & 35 & 10 & 46 & 91 \\
\hline 2004 & & 21 & 6 & 57 & 84 \\
\hline 2005 & & 27 & 14 & 41 & 82 \\
\hline 2006 & & 32 & 12 & 29 & 73 \\
\hline 2007 & & 34 & 8 & 48 & 90 \\
\hline
\end{tabular}


Table 9: $\quad$ Emergencies at level crossings and consequences.

\begin{tabular}{|c|c|c|c|c|}
\hline \multirow{2}{*}{ Year } & \multirow{2}{*}{$\begin{array}{c}\text { Number of } \\
\text { emergencies at } \\
\end{array}$} & \multicolumn{3}{|c|}{ Emergency consequences } \\
\cline { 3 - 5 } & level crossings & Material damage & \multicolumn{2}{|c|}{ Victims } \\
\cline { 3 - 5 } & & $\begin{array}{c}\text { fractures of half- } \\
\text { barriers / barriers }\end{array}$ & fatalities & seriously injured \\
\hline 2001 & 68 & 444 & 12 & 22 \\
\hline 2002 & 69 & 457 & 12 & 31 \\
\hline 2003 & 64 & 504 & 6 & 26 \\
\hline 2004 & 68 & 566 & 16 & 13 \\
\hline 2005 & 87 & 541 & 16 & 25 \\
\hline 2006 & 78 & 639 & 12 & 19 \\
\hline 2007 & 71 & 683 & 91 & 148 \\
\hline Total & 505 & 3834 & & \\
\hline
\end{tabular}

\section{Evaluation of the safety condition at LCs in Croatia}

The analysis of the research carried out and the statistical data during the sevenyear period on the incidents at LCs and their consequences has led to the following conclusions:

- the share of LC accidents in the total number of traffic accidents in road traffic amounts to $0.693 \%$, which is a much higher share than in the EU countries where it amounts to $0.01 \%$;

- the share of fatalities in LC accidents out of the total number of fatalities in traffic accidents in road traffic amounts to $1.858 \%$, which also represents a much higher share than in the EU countries where it is less than $1 \%$;

- the data of 550 average annual collisions and fractures of barriers, as well as the frequency of crossing the railway line at LCs with the half-barrier / barrier lowered and the light-sound signalization turned on, proves inadequate behaviour of traffic participants which is in the majority of cases the cause of emergencies with the most serious consequences;

- in a significant number of LCs that are protected only by adequate traffic sign (STOP or St. Andrew's cross), there is no visibility triangle;

- the problem of unstandardized and unique monitoring of data, structure methodology and data processing at the authorized institutions (Croatian railways), Ministry of the Interior, road operators) which results from the absence of a unique base and joint information system;

- lack of uniformity of the legislation at the European level.

\section{Conclusion and proposal for future research}

LCs are points of conflict between rail and road traffic and potentially high-risk traffic points. Since a share of accidents at LCs in the total number of road traffic accidents ranges on the average at around $0.01 \%$, and in rail traffic from $50-80 \%$, 
it may be concluded that the safety and the improvement measures of the system lie in the responsibility of the railways. However, the statistical data also show that in more than $90 \%$ of emergencies the main causes lie in the road vehicle drivers and pedestrians. Besides, there is a significant number of accidents at LCs protected by devices during their proper operation which is also an indicator of extremely low level of drivers' compliance with the traffic regulations. Therefore, the safety problem at LCs is a common problem both of rail and road sectors, and for its efficient solving there has to be cooperation between both sectors.

The measures for the improvement of the current system are the basis for further research and can be grouped in three basic categories:

- technological and technical aspect - adoption of new technologies and advanced technical solutions,

- human factor - education of traffic participants in order to improve the traffic discipline and the culture of drivers,

- legislation - monitoring and participation in harmonizing the European legislation and its implementation into the national legislation.

Only systemic and continuous implementation of measures and actions in compliance with the Program of solving LCs in the area of technical and technological solutions as well as in the area of educating the traffic participants may eventually result in the improvement of the current condition and in achieving higher safety of rail and road traffic at LCs.

\section{References}

[1] Statistical information, Republic of Croatia Central Bureau of Statistics, Zagreb, 2008.

[2] Badanjak, D., Bogović, B., Jenić, V.: Organization of railway transportation, Faculty of Transport and Traffic Sciences, Zagreb, 2006.

[3] Safer European Level Crossing Appraisal and Technology, Second Workshop "Technology", Marrakesh, Proceedings

[4] Program of restructuring LCs, The Ministry of the Sea, Tourism, Transport and Development, Railway Traffic Authority, Zagreb, 2006

[5] National Program of railway infrastructure for period 2008-2010, NN 31/08

[6] Law on railways, NN 123/03, 194/03, 30/04, 79/07

[7] Law on rail traffic safety, NN 40/07

[8] Decision on classification of railway lines, NN 81/06

[9] Regulations on criteria, procedure, method of defining and protection of rail-road crossings, NN 32/94, 96/94, 33/01, 122/03, 83/04

[10] Statistical data of Croatian railways, Zagreb, 2008

[11] Bulletin of the Ministry of the Interior, Ministry of the Interior, 2007, Zagreb 